\title{
Long non-coding RNA transcribed from pseudogene PPIAP43 is associated with radiation sensitivity of small cell lung cancer cells
}

\author{
SHILONG WANG ${ }^{1,2}$ and JINMING YU $\mathrm{U}^{2,3}$ \\ ${ }^{1}$ Cheeloo College of Medicine, Shandong University, Jinan, Shandong 250012; \\ ${ }^{2}$ Department of Radiation Oncology, Shandong Cancer Hospital Affiliated to Shandong University; \\ ${ }^{3}$ Department of Radiation Oncology, Shandong Cancer Hospital and Institute, Shandong Academy of Medical Sciences, \\ Jinan, Shandong 250117, P.R. China
}

Received February 20, 2019; Accepted July 26, 2019

DOI: $10.3892 / \mathrm{ol} .2019 .10806$

\begin{abstract}
Small cell lung cancer (SCLC) is a highly lethal disease. Although radiation therapy is effective for the majority of patients with SCLC, patient sensitivity to radiation varies. The lack of biomarkers impedes advances in targeting radiation-sensitive patients. In this study, the changes in transcription patterns of SCLC cell lines were evaluated with or without 2 Gy gamma radiation. The results demonstrated that peptidyl-prolyl cis-trans isomerase A pseudogene 43 (PPIAP43) transcription was increased 2-fold in cells irradiated with 2 Gy gamma radiation compared with unirradiated cells in pre-reported radio-sensitive sensitive cell lines H69, H128, H146, H209 and H187. These cells shared 259 upregulated and 96 downregulated RNA transcripts following radiation. Pre-reported less sensitive cell lines H526, D53, D114 and D153 in which PPIAP43 was not upregulated 2-fold following irradiation with $2 \mathrm{~Gy}$ gamma radiation compared with unirradiated cells, shared 3 upregulated and 9 downregulated RNA transcripts. The RNA transcript of PPIAP43 was aligned with the mRNA of peptidyl-prolyl cis-trans isomerase A (PPIA) at 2 sections (3,732 to 3,917 and 5,327 to 5,657 of the PPIA gene) and the sequences were shown to be 96 and 94\% similar, respectively. Therefore, PPIAP43 may act as a
\end{abstract}

Correspondence to: Dr Jinming Yu, Department of Radiation Oncology, Shandong Cancer Hospital Affiliated to Shandong University, 440 Jiyan Road, Jinan, Shandong 250117, P.R. China

E-mail: sdyujinming@163.com

Abbreviations: SCLC, small cell lung cancer; RT, radiation therapy; PPIA, peptidyl-prolyl cis-trans isomerase A; PPIAP43, peptidyl-prolyl cis-trans isomerase A pseudogene 43; miRNA, micro RNA; lncRNA, long non-coding RNA; GO, Gene Ontology; DEG, differentially expressed gene; BLAST, Basic Local Alignment Searching Tool; DAVID, the Database for Annotation, Visualization and Integrated Discovery; KEGG, Kyoto Encyclopedia of Genes and Genomes; ARHGAP42, Rho GTPase activating protein 42; PPIAL4A, peptidyl-prolyl cis-trans isomerase A like 4A.

Key words: small cell lung cancer cell lines, radiation sensitivity, potential biomarker, PPAP43, Cyclophilin A sponge for microRNAs which bind with the RNA of PPIA. Therefore, PPIAP43 RNA transcription may serve as a potential biomarker of radio-sensitivity of SCLC.

\section{Introduction}

Small cell lung cancer (SCLC) is a highly malignant cancer. According to a recent review, SCLC accounts for approximately $15 \%$ of cases of lung cancers in the USA (2014), UK (2014), China (2014) and Korea (2016) (1). Regardless of the progression of the treatment for the other types of lung cancer, such as targeted therapy and immunotherapy, the most common therapeutic options for SCLC are traditional chemotherapy, radiation therapy (RT) and surgical therapy (2). The outcome of SCLC has not improved considerably, and the five-year survival of SCLC is only $7 \%$ (1). Thus, besides pioneering new therapies, modification of traditional ones is needed, and radiation therapy as a major treatment option for SCLC needs to be refined.

The effects of RT include undesirable side effects on normal tissues (3). Normally, a higher curative effect and a lower side effect are desirable. Advanced technologies such as intensity-modulated and stereotactic body RT can limit the irradiation area $(4,5)$; however, to further avoid damage to normal tissue, it is important to determine whether the cancer cells are sensitive to radiation as early as possible. At present, there are no biomarkers in clinical use for predicting the effectiveness of RT on certain types of the disease.

Next generation sequencing (NGS) technology provides high throughput data of gene-transcribed mRNAs and RNAs transcribed from the non-coding regions. The National Center for Biotechnology Information (NCBI) Gene Expression Omnibus (GEO) database enables mass exploration of data to obtain precise and comprehensive information on diseases. With these tools, the present study aimed to find a potential biomarker for prediction the effectiveness of radiation therapy on SCLC by mining in the databases.

\section{Materials and methods}

Datasets. The gene expression data GSE55830 was collected from NCBI GEO datasets (6). This dataset comprises data of different SCLC cell lines (H69, H128, H146, H209, H187, H526, 
D53, D114 and D153) treated with various therapeutic methods including radiation therapy and chemotherapy, as well as controls. The experiment was based on Illumina HumanHT-12 V4.0 expression beadchip (GPL10558). BRB-ArrayTools integrated in Excel 2016 (Microsoft Corporation) was used to display the data with default parameters (7).

Identification of the underlying targets. The 'Array vs. Array' module in BRB-ArrayTools was used to display the differentially expressed sequences between radiation-treated and the control arrays of each cell line on a $\log 2$ scale.

Classification of differentially expressed genes (DEGs). Cell lines were divided into two groups with a cut-off of 2 -fold transcription change of the chosen sequence in the former step. Each cell line was respectively categorized as group A when the transcription levels of PPIAP43 were increased $\geq 2$ fold following 2 Gy gamma radiation compared with the unirradiated control cells, or group $B$ when the transcription levels of PPIAP43 were decreased or increased $<2$ fold following 2 Gy gamma radiation compared with the unirradiated control cells. The two groups were processed by the class comparison module between controls and radiation groups paired by cell line names.

Functional clustering of the differentially expressed genes and pathway determination. The upregulated and downregulated genes in the radiation group were analyzed by the Database for Annotation, Visualization and Integrated Discovery online tool for Gene Ontology (GO) annotation and Kyoto Encyclopedia or Genes and Genomes (KEGG) pathway determination $(8,9)$.

Detection of adjacent genes. NCBI Gene database was used to identify the adjacent genes, the transcription of which can be affected by the pseudogene. The transcription changes of the adjacent gene and the pseudogene PPIAP43 were calculated as the difference between radiation and the control group normalized to the control value: Fold change $=$ (radiation-control $) /$ control.

Detection of protein candidates interacting with the RNA transcript. The RNA transcript of the pseudogene was uploaded in the catRAPID omics 'transcript vs nucleotide-binding proteome' module of the catRAPID online toolkits (10). This tool identified a series of proteins that may bind with the target nucleotide.

MicroRNA (miRNA) determination. miRDB online $(11,12)$ was used to align potential miRNAs with RNA transcripts of pseudogenes PPIAP43 and PPIA.

Basic Local Alignment Searching Tool (BLAST) of peptidyl-prolyl cis-trans isomerase A (PPIA) and PPIAP43. NCBI BLAST (https://blast.ncbi.nlm.nih.gov/Blast.cgi) was used to align the DNA sequences with pseudogene PPIAP43 and PPIA.

Database construction. Microsoft Access 2016 (Microsoft Corporation) was used for managing and relate the data across different tables.

\section{Results}

Screening upregulated and downregulated expression nucleotides after 2 Gy gamma radiation in each cell line. A total of 6,034 genes were displayed in Excel, and nine cell lines comprising H69, H128, H146, H187, H209, H526, D53, D114 and D153 were extracted from the dataset. PPIAP43 was upregulated by $\geq 2$-fold in H69, H128, H146, H209 and H187 following radiation compared with non-irradiated controls, and was the only upregulated transcript in former four cell lines and one of the two in the H187 cell line (Tables I and II; Fig. 1). No $\geq 2$-fold downregulated transcripts were identified in H69, H128, H146, H209 and H187 cells (Table II; Fig. 1). TAF15 was the only downregulated transcript in H114, whereas no upregulated transcripts were identified. In H526 and D153, no transcripts were differentially expressed. Multiple differentially expressed RNAs were only identified in D53, all of which were upregulated. These findings were based on the criterion of $\geq 2$-fold change (Table II).

Detection of differentially expressed genes. Considering the similarity of expression change patterns among H69, H128, H146, H209 and H187 cells and the difficulty to determine discovery with the lack of adequate cell types of each expression change pattern in the other four cell lines, the cell lines were divided into two groups, with H69, H128, H146, H209 and H187 labeled group A, and H526, D53, D114 and D153 labeled group B. Group A was assessed using a t-test (with a random variance model) class comparison between the radiation and control groups paired by cell type with a $\mathrm{P}<0.001$ nominal significance threshold of univariate tests. A total of 355 transcripts passed the filter with 259 upregulated and 96 downregulated transcripts (Fig. 2). False discovery rates (FDRs) were <0.018; the FDR of ILMN_3208715, which was annotated as PPIAP43, was $<1 \times 10^{-7}$. Top five upregulated genes or pseudogenes in group A are presented in Table II. Group B was processed by the same algorithm; three upregulated and nine downregulated transcripts were identified on average. The transcription patterns of the two groups before and after radiation were distinguishable from each other (Fig. 3). The genes highly expressed before and after radiation in radiosensitive group A compared with group B were identified to be genes that are highly expressed in normal testis and lymph nodes. The genes highly expressed before and after radiation in radiosensitive group B compared with group A were related with the cell cycle (Table III). Although P-values of these differentially expressed genes between the radiation and control of group B were all $<0.001$, FDRs were $>0.05$, with the lowest FDR=0.0658.

GO function and KEGG pathway analysis. Upregulated and downregulated genes in group A were uploaded in DAVID. Although there were more upregulated transcripts compared with downregulated transcripts, the upregulated genes were involved in fewer (four pathways in total) and less reliable pathways ( $\mathrm{P}>0.01$ in all 4 pathways) (Table IVA). By contrast, 22 pathways were identified in the downregulated genes; four of these genes exhibited $\mathrm{P}<0.01$ (Table IVB).

mRNA transcription from an adjacent protein-coding gene is negatively correlated with the transcription of PPIAP43. 
Table I. Experimental design.

\begin{tabular}{lcccc}
\hline Cell line & Experiment ID of control & Experiment ID of radiation & PPIAP43 over transcribed & Group \\
\hline H69 & GSM1346757 & GSM1346806 & Yes & Yes \\
H128 & GSM1346758 & GSM1346808 & Yes \\
H146 & GSM1346769 & GSM1346810 & Yes & A \\
H187 & GSM1346770 & GSM1346812 & A \\
H209 & GSM1346781 & GSM1346814 & A \\
H526 & GSM1346782 & GSM1346816 & No & B \\
D53 & GSM1346793 & GSM1346817 & No & B \\
D114 & GSM1346794 & GSM1346818 & No & B \\
D153 & GSM1346805 & GSM1346819 & \\
\hline
\end{tabular}

Table II. Transcripts with an up or downregulated transcriptional fold change $\geq 2$-fold following 2 Gy gamma radiation in each small cell lung cancer cell line.

A, Upregulated transcripts

\begin{tabular}{|c|c|c|c|c|c|}
\hline Cell line & ID & Transcript & ILMN gene & Entrez gene ID & Cytoband \\
\hline H69 & ILMN_3208715 & ILMN_162197 & PPIAP43 & 440063 & $11 \mathrm{q} 22.1 \mathrm{c}$ \\
\hline H128 & ILMN_3208715 & ILMN_162197 & PPIAP43 & 440063 & $11 \mathrm{q} 22.1 \mathrm{c}$ \\
\hline H146 & ILMN_3208715 & ILMN_162197 & PPIAP43 & 440063 & $11 \mathrm{q} 22.1 \mathrm{c}$ \\
\hline H209 & ILMN_3208715 & ILMN_162197 & PPIAP43 & 440063 & $11 \mathrm{q} 22.1 \mathrm{c}$ \\
\hline H187 & ILMN_3208715 & ILMN_162197 & PPIAP43 & 440063 & $11 \mathrm{q} 22.1 \mathrm{c}$ \\
\hline H187 & ILMN_3251587 & ILMN_177351 & LOC100008589 & 100008589 & \\
\hline D53 & ILMN_1656868 & ILMN_45317 & LOC23117 & 23117 & $16 \mathrm{p} 12.2 \mathrm{a}$ \\
\hline D53 & ILMN_1772492 & ILMN_22327 & MCART1 & 92014 & $9 \mathrm{p} 13.2 \mathrm{a}$ \\
\hline D53 & ILMN_1807291 & ILMN_175467 & CYP1A1 & 1543 & $15 q 24.1 b$ \\
\hline D53 & ILMN_1892403 & ILMN_168446 & SNORD13 & 692084 & $8 \mathrm{p} 12 \mathrm{c}$ \\
\hline D53 & ILMN_2070052 & ILMN_25996 & LOC613037 & 613037 & $16 \mathrm{p} 11.2 \mathrm{~d}$ \\
\hline D53 & ILMN_2075794 & ILMN_169055 & NLRP8 & 126205 & $19 q 13.42 \mathrm{c}$ \\
\hline D53 & ILMN_2117809 & ILMN_17811 & DUXAP3 & 503632 & $10 \mathrm{q} 11.21 \mathrm{a}$ \\
\hline D53 & ILMN_2162367 & ILMN_167637 & DMC1 & 11144 & $22 \mathrm{q} 13.1 \mathrm{~b}-\mathrm{q} 13.1 \mathrm{c}$ \\
\hline D53 & ILMN_2342455 & ILMN_15173 & PPA2 & 27068 & $4 q 24 d$ \\
\hline D53 & ILMN_3243664 & ILMN_20243 & LOC440353 & 440353 & $16 \mathrm{p} 11.2 \mathrm{~d}$ \\
\hline D53 & ILMN_3304111 & ILMN_347878 & LOC729978 & 729978 & $16 \mathrm{p} 13.13 \mathrm{~b}$ \\
\hline D53 & ILMN_3310491 & ILMN_388662 & MIR1978 & 100302173 & \\
\hline
\end{tabular}

B, Downregulated transcripts

\begin{tabular}{llllll}
\hline Cell line & ID & Transcript & ILMN Gene & Entrez gene ID & Cytoband \\
\hline D114 & ILMN_1678707 & ILMN_18523 & TAF15 & 8148 & $17 q 12 b$ \\
\hline
\end{tabular}

Pearson correlation analysis of transcriptional changes between PPIAP43 and ARHGAP42 showed the correlation coefficient was $-0.584(\mathrm{P}=0.099)$ suggesting that there was no statistically significant correlation between transcriptional changes of PPIAP43 and ARHGAP42. The adjacent transcription effects of the pseudogene PPIAP43 on the only nearby coding gene Rho GTPase activating protein 42 (ARHGAP42) were limited, as previous studies suggested that the transcription of lncRNA is positively correlated with transcription of nearby protein-coding genes if there is an effect on adjacent protein-coding genes by lncRNA transcription $(13,14)$. The transcription levels of PPIAP43 and ARHGAP42 changed in opposite directions following radiation (Fig. 4). Of note, no P-value of the expression of ARHGAP42 in the original dataset was $<0.01$, which may be a limitation of this evaluation. 

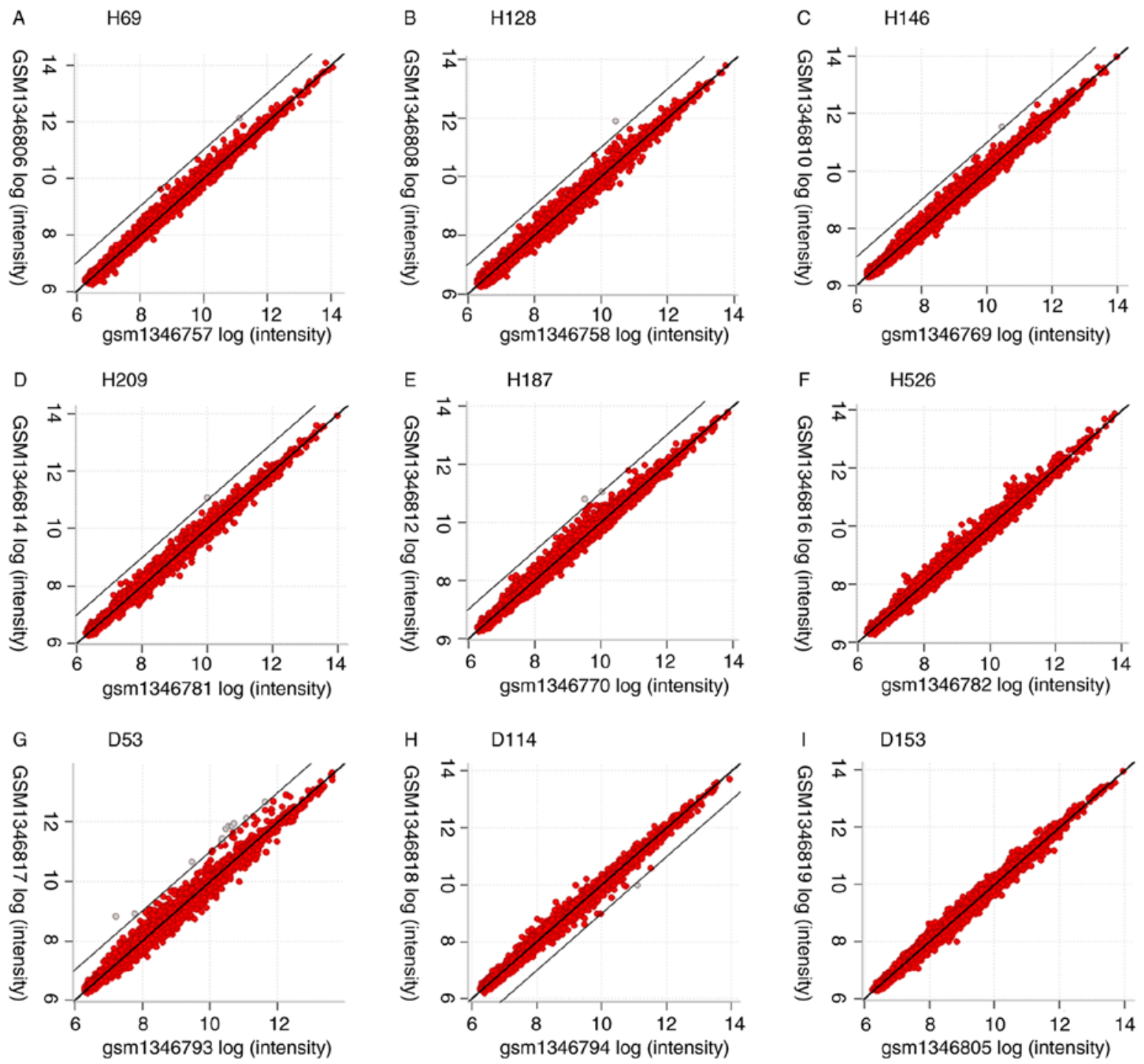

Figure 1. Genes with an up or downregulated transcriptional fold change $\geq 2$ following irradiation with 2 Gy gamma radiation compared with unirradiated controls. PPIAP43 was the only upregulated transcript in cell line (A) H69, (B) H128, (C) H146 and (D) H209, and (E) one of the two in H187. (F) No genes were upregulated or downregulated in H526. (G) Multiple differentially expressed RNAs were identified in D53, all of which were upregulated. (H) TAF15 was the only downregulated transcript in D114, whereas no upregulated transcripts were detected. (I) No genes were upregulated or downregulated in D153. The results were based on $\geq 2$-fold change. The white circles represent the genes and pseudogenes of which up or downregulation of transcription was $\geq 2$-fold following irradiation with $2 \mathrm{~Gy}$ gamma radiation compared with unirradiated controls. The red circles represent the represent the genes and pseudogenes with $<2$ fold change in expression following irradiation. PPIAP43, PPIAP43, peptidyl-prolyl cis-trans isomerase A pseudogene 43; TAF15, TATA-box binding protein-associated factor 15 .

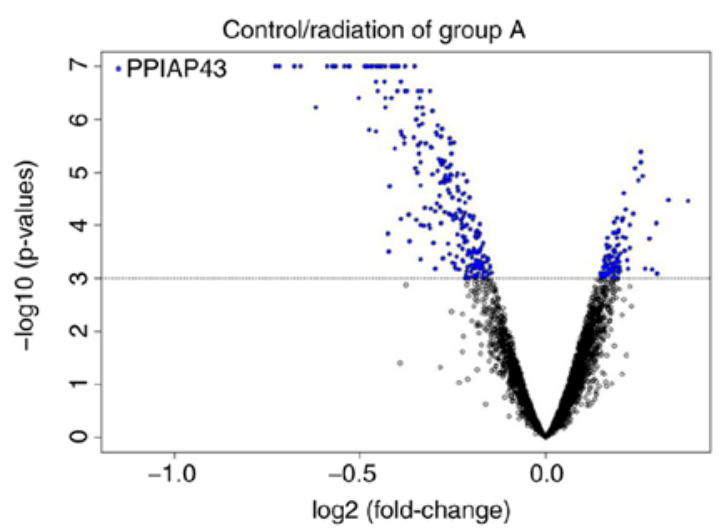

Figure 2. Differentially expressed genes and pseudogenes in control vs. radiation groups of cell lines in group $\mathrm{A}(\mathrm{P}<0.001 ; \mathrm{FDR}<0.018)$. The far top left point corresponds to PPIAP43 $\left(\mathrm{P}<1 \times 10^{-7} ; \mathrm{FDR}<1 \times 10^{-7}\right)$. PPIAP43, PPIAP43, peptidyl-prolyl cis-trans isomerase A pseudogene 43; FDR, false discovery rate.
Proteins predicted to interact with the identified $\operatorname{lncRNA}$. The sequence of the RNA transcript of PPIAP43 was uploaded to the catRAPID omics 'transcript vs. nucleotide-binding proteome' module of the catRAPID online toolkits (http://service.tartaglialab.com/page/catrapid_group). The identified 118 proteins as candidates that may bind with the RNA transcript of PPIAP43. Of these, nine proteins, including TIAR, SRS10, SRSF2, TRA2B, TIA1, SFPQ, SRSF7, SRSF9 and PCBP2 were marked by catRAPID omics with necessary domains and motifs for nucleotide-binding. These nine proteins were annotated by DAVID to serve functions in nucleotide binding and splicing proteins (Table V).

BLAST of PPIA and the pseudogenes. Two aligned sections (3732 to 3917 and 5327 to 5657 of the PPIA gene sequence with identities of 96 and 94\%, respectively) were identified on RNA 
Table III. Differentially expressed genes with different probes consecutively expressed before and after radiation.

\begin{tabular}{|c|c|c|c|c|c|c|}
\hline UniqueID & Gene name & $\begin{array}{l}\text { Before } \\
\text { P-value }\end{array}$ & $\begin{array}{c}\text { Before } \\
\text { fold change }\end{array}$ & $\begin{array}{c}\text { After } \\
\text { P-value }\end{array}$ & $\begin{array}{c}\text { After } \\
\text { fold change }\end{array}$ & Function \\
\hline ILMN_2231003 & MAGEA12 & 0.000993 & 0.28 & 0.000689 & 0.25 & $\begin{array}{l}\text { Highly expressed } \\
\text { in normal testis }\end{array}$ \\
\hline ILMN_2412880 & CSAG3B & 0.000009 & 0.32 & 0.000011 & 0.31 & $\begin{array}{l}\text { Highly expressed } \\
\text { in normal testis, lymph } \\
\text { node and spleen }\end{array}$ \\
\hline ILMN_1718107 & MAGEA12 & 0.000288 & 0.30 & 0.000376 & 0.32 & $\begin{array}{l}\text { Highly expressed } \\
\text { in normal testis }\end{array}$ \\
\hline ILMN_1761122 & CSAG3B & 0.000030 & 0.39 & 0.000028 & 0.40 & $\begin{array}{l}\text { Highly expressed in } \\
\text { normal testis, lymph node } \\
\text { and spleen }\end{array}$ \\
\hline ILMN_2297352 & CSAG3B & 0.000026 & 0.45 & 0.000078 & 0.48 & $\begin{array}{l}\text { Highly expressed in } \\
\text { normal testis, lymph } \\
\text { node and spleen }\end{array}$ \\
\hline ILMN_3260910 & CSAG3 & 0.000014 & 0.56 & 0.000060 & 0.54 & $\begin{array}{l}\text { Highly expressed } \\
\text { in normal testis, lymph } \\
\text { node and spleen }\end{array}$ \\
\hline ILMN_1803852 & LOC653297 & 0.000528 & 0.59 & 0.000693 & 0.61 & Similar to CSAG3B \\
\hline ILMN_2328813 & DMAP1 & 0.000198 & 1.85 & 0.000290 & 1.84 & $\begin{array}{l}\text { Transcription repression } \\
\text { and activation }\end{array}$ \\
\hline ILMN_1740319 & IFI27L2 & 0.000195 & 2.23 & 0.000454 & 1.99 & Apoptosis \\
\hline ILMN_1810486 & RAB34 & 0.000659 & 2.57 & 0.000836 & 2.33 & $\begin{array}{l}\text { Repositioning of lysosomes } \\
\text { and the activation } \\
\text { of macropinocytosis }\end{array}$ \\
\hline ILMN_3238560 & IFI27L2 & 0.000095 & 2.68 & 0.000137 & 2.64 & Apoptosis \\
\hline ILMN_1708006 & MICB & 0.000798 & 3.28 & 0.000683 & 3.14 & $\begin{array}{l}\text { Stress-induced } \\
\text { self-antigen }\end{array}$ \\
\hline ILMN_1796712 & S100A10 & 0.000095 & 3.96 & 0.000187 & 3.80 & $\begin{array}{l}\text { Cell cycle progression } \\
\text { and differentiation }\end{array}$ \\
\hline ILMN_2046730 & S100A10 & 0.000024 & 7.34 & 0.000036 & 6.95 & $\begin{array}{l}\text { Cell cycle progression } \\
\text { and differentiation }\end{array}$ \\
\hline
\end{tabular}
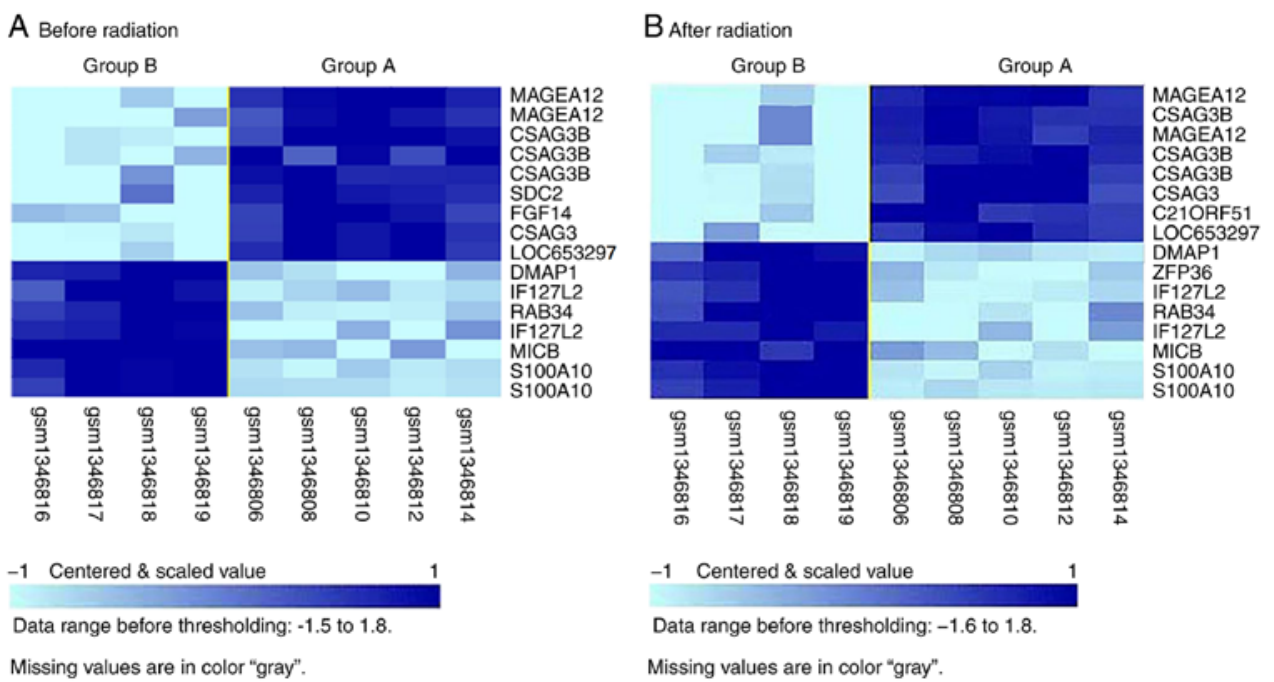

Figure 3. Differentially expressed genes with different gene probes: ILMN_2231003, ILMN_1718107 for MAGEA12; ILMN_2297352, ILMN_1761122, ILMN_2412880 for CSAG3B; ILMN_1784553 for SDC2; ILMN_1732976 for FGF14; ILMN_3260910 for CSAG3; ILMN_1803852 for LOC653297; ILMN_2328813 for DMAP1; ILMN_1740319, ILMN_3238560 for IFI27L2; ILMN_1810486 for RAB34; ILMN_1708006 for MICB; ILMN_1796712, ILMN_2046730 for S100A10; ILMN_2356311 for C21ORF51; ILMN_1720829 for ZFP36, were consecutively expressed (A) before and (B) after radiation. 
Table IV. Pathways of upregulated and downregulated genes in group A after radiation.

A, pathways of upregulated genes

\begin{tabular}{|c|c|c|c|c|c|c|}
\hline Category & Term & Count & $\%$ & P-value & List total & Fold enrichment \\
\hline KEGG_PATHWAY & $\begin{array}{l}\text { hsa01100: } \\
\text { Metabolic pathways }\end{array}$ & 19 & 8.558559 & 0.018995 & 63 & 1.701902 \\
\hline KEGG_PATHWAY & hsa04110:Cell cycle & 5 & 2.252252 & 0.025133 & 63 & 4.402842 \\
\hline KEGG_PATHWAY & $\begin{array}{l}\text { hsa00270:Cysteine and } \\
\text { methionine metabolism }\end{array}$ & 3 & 1.351351 & 0.045657 & 63 & 8.620301 \\
\hline KEGG_PATHWAY & $\begin{array}{l}\text { hsa03420:Nucleotide } \\
\text { excision repair }\end{array}$ & 3 & 1.351351 & 0.066706 & 63 & 6.969605 \\
\hline
\end{tabular}

B, pathways of downregulated genes

\begin{tabular}{|c|c|c|c|c|c|c|}
\hline Category & Term & Count & $\%$ & P-value & List total & Fold enrichment \\
\hline UP_KEYWORDS & Phosphoprotein & 44 & 55 & 0.000379 & 72 & 1.525258 \\
\hline UP_KEYWORDS & Cytoplasm & 29 & 36.25 & 0.001841 & 72 & 1.721256 \\
\hline UP_KEYWORDS & Methylation & 11 & 13.75 & 0.002205 & 72 & 3.141178 \\
\hline UP_KEYWORDS & Alternative splicing & 49 & 61.25 & 0.004189 & 72 & 1.322992 \\
\hline UP_KEYWORDS & Ubl conjugation & 13 & 16.25 & 0.013193 & 72 & 2.179480 \\
\hline UP_KEYWORDS & Coated pit & 3 & 3.75 & 0.013416 & 72 & 16.814542 \\
\hline UP_KEYWORDS & Golgi apparatus & 8 & 10 & 0.021676 & 72 & 2.816229 \\
\hline UP_KEYWORDS & Endosome & 6 & 7.5 & 0.025215 & 72 & 3.565662 \\
\hline UP_KEYWORDS & Cell junction & 7 & 8.75 & 0.028843 & 72 & 2.964342 \\
\hline UP_KEYWORDS & Membrane & 35 & 43.75 & 0.030912 & 72 & 1.335022 \\
\hline UP_KEYWORDS & $\begin{array}{l}\text { Dyskeratosis } \\
\text { congenita }\end{array}$ & 2 & 2.5 & 0.037309 & 72 & 51.972222 \\
\hline UP_KEYWORDS & Acetylation & 19 & 23.75 & 0.039913 & 72 & 1.586185 \\
\hline UP_KEYWORDS & Cytoskeleton & 9 & 11.25 & 0.041696 & 72 & 2.260655 \\
\hline KEGG_PATHWAY & $\begin{array}{l}\text { hsa04530: } \\
\text { Tight junction }\end{array}$ & 3 & 3.75 & 0.048329 & 29 & 8.179548 \\
\hline UP_KEYWORDS & Endocytosis & 3 & 3.75 & 0.065530 & 72 & 7.087121 \\
\hline INTERPRO & $\begin{array}{l}\text { IPR012677: } \\
\text { Nucleotide-binding, } \\
\text { alpha-beta plait }\end{array}$ & 4 & 5 & 0.067759 & 67 & 4.196970 \\
\hline UP_KEYWORDS & Microtubule & 4 & 5 & 0.072561 & 72 & 4.083532 \\
\hline UP_KEYWORDS & Autophagy & 3 & 3.75 & 0.074222 & 72 & 6.596474 \\
\hline UP_KEYWORDS & Ribonucleoprotein & 4 & 5 & 0.082570 & 72 & 3.862800 \\
\hline UP_KEYWORDS & Oxidation & 2 & 2.5 & 0.089138 & 72 & 21.173868 \\
\hline UP_KEYWORDS & Isopeptide bond & 8 & 10 & 0.094746 & 72 & 2.020122 \\
\hline KEGG_PATHWAY & $\begin{array}{l}\text { hsa04611: } \\
\text { Platelet activation }\end{array}$ & 3 & 3.75 & 0.097433 & 29 & 5.474005 \\
\hline
\end{tabular}

transcripts of PPIAP43 and PPIA, with the second aligned section (5327 to 5657) located primarily in the 3'-untranslated region (UTR) of PPIA mRNA (Table VI). In addition, PPIA pseudogenes PPIAP33, PPIAP80, PPIAP35 which were also upregulated by radiation, were aligned with PPIA in two sections similar to PPIAP43.

miRNA binding with PPIAP43 and PPIA or peptidyl-prolyl cis-trans isomerase A like 4A (PPIAL4A). A total of 12 and 28 miRNAs were predicted to be able to bind with the RNA transcripts of PPIAP43 and PPIA, respectively. By contrast, only one miRNA hsa-miR-876-3p, whose binding ability had been confirmed by 91 RNA-seq reads from 21 experiments, was predicted to be able to bind with PPIAP43 and PPIA. There was one binding site on PPIAP43 (target score, 74/100) and three binding sites on PPIA (target score, 92/100) (Table VI). Two of the PPIA binding sites were on pre-mRNA, and one was on the 3'UTR. By contrast, 
Table V. Annotation of protein candidates to bind with the RNA transcript of PPIAP43.

\begin{tabular}{|c|c|c|c|c|c|c|}
\hline Category & Term & Count & P-value & Genes & Pop hits & FDR \\
\hline $\begin{array}{l}\text { GOTERM_MF_ } \\
\text { DIRECT }\end{array}$ & $\begin{array}{l}\text { GO:0000166 nucleotide } \\
\text { binding }\end{array}$ & 6 & $<0.001$ & $\begin{array}{l}\text { SRSF2, SRSF7, } \\
\text { SFPQ, TIA1, } \\
\text { SRSF9, TRA2B }\end{array}$ & 253 & $<0.001$ \\
\hline $\begin{array}{l}\text { GOTERM_BP_- } \\
\text { DIRECT }\end{array}$ & $\begin{array}{l}\text { GO:0048025 negative } \\
\text { regulation of mRNA } \\
\text { splicing, via spliceosome }\end{array}$ & 3 & $<0.001$ & $\begin{array}{l}\text { SRSF7, } \\
\text { SRSF9, TRA2B }\end{array}$ & 14 & 0.0132 \\
\hline $\begin{array}{l}\text { GOTERM_MF_ } \\
\text { DIRECT }\end{array}$ & $\begin{array}{l}\text { GO:0036002 pre- } \\
\text { mRNA binding }\end{array}$ & 2 & 0.0036 & SRSF2, TRA2B & 6 & 2.1484 \\
\hline $\begin{array}{l}\text { GOTERM_MF_ } \\
\text { DIRECT }\end{array}$ & $\begin{array}{l}\text { GO:0044822 poly(A) } \\
\text { RNA binding }\end{array}$ & 4 & 0.0089 & $\begin{array}{l}\text { SRSF7, TIA1, } \\
\text { SRSF9, POP1 }\end{array}$ & 789 & 5.2146 \\
\hline $\begin{array}{l}\text { GOTERM_BP_- } \\
\text { DIRECT }\end{array}$ & $\begin{array}{l}\text { GO:0000381 regulation } \\
\text { of alternative mRNA } \\
\text { splicing, via spliceosome }\end{array}$ & 2 & 0.0136 & SRSF2, TRA2B & 28 & 9.5745 \\
\hline
\end{tabular}

FDR, false discovery rate; SRSF2, serine and arginine rich splicing factor 2; SRSF7, serine and arginine rich splicing factor 7; SFPQ, splicing factor proline and glutamine rich; TIA1, t-cell-restricted intracellular antigen-1; SRSF9, serine and arginine rich splicing factor 9; TRA2B, transformer 2 beta homolog; POP1, processing of precursors 1.

Table VI. MicroRNAs with the ability to bind with the RNA transcript of PPIAP43 and mRNAs of PPIA and PPIAL4A.

\begin{tabular}{|c|c|c|c|c|c|c|}
\hline Gene name & miRNA & $\begin{array}{c}\text { PPIAP43 transcript } \\
\text { target score }\end{array}$ & $\begin{array}{l}\text { PPIAP43 transcript } \\
\text { target site number }\end{array}$ & $\begin{array}{c}\text { Gene transcript } \\
\text { target score }\end{array}$ & $\begin{array}{l}\text { mRNA target } \\
\text { site number }\end{array}$ & $\begin{array}{l}\text { Binding } \\
\text { locations }\end{array}$ \\
\hline PPIA & hsa-miR-876-3p & 74 & 1 & 92 & 1 & $\begin{array}{c}5485 \\
\left(3^{\prime} \mathrm{UTR}\right)\end{array}$ \\
\hline PPIAL4A & hsa-miR-4288 & 79 & 1 & 87 & 1 & 151 \\
\hline PPIAL4A & hsa-miR-4456 & 72 & 1 & 52 & 1 & 597 \\
\hline PPIAL4A & hsa-miR-1825 & 59 & 2 & 55 & 2 & 194,290 \\
\hline
\end{tabular}

PPIA, peptidyl-prolyl cis-trans isomerase A; PPIAL4A, peptidyl-prolyl cis-trans isomerase A like 4A; PPIAP43, peptidyl-prolyl cis-trans isomerase A pseudogene 43; miR, miRNA, microRNA.

\section{A PPIAP43-ARHGAP42} ((radiation-con)/con)

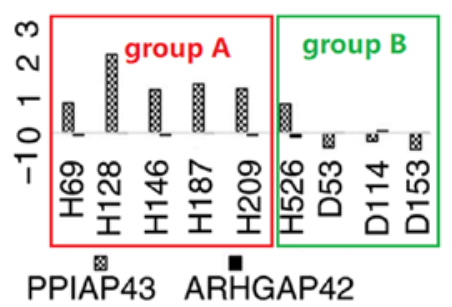

\section{B PPIAP43-PPIAL4A-PPIA ((radiation-con)/con)}

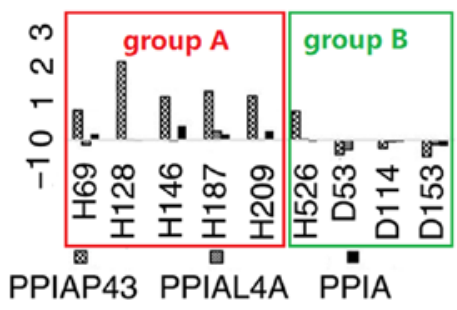

Figure 4. Transcriptional changes of PPIAP43, ARHGAP42, PPIAL4A and PPIA following irradiation with 2 Gy gamma radiation in each cell line. (A) Fold change of PPIAP43 and its adjacent gene ARHGAP42 transcripts in cell lines. (B) Fold change of PPIAP43, PPIAL4A and PPIA transcripts; the values were calculated as the difference between radiation and control group normalized to the control value as follows: Fold change $=($ radiation-control $) / \mathrm{control}$. PPIA, peptidyl-prolyl cis-trans isomerase A; PPIAL4A, peptidyl-prolyl cis-trans isomerase A like 4A; PPIAP43, peptidyl-prolyl cis-trans isomerase A pseudogene 43; ARHGAP42, Rho GTPase activating protein 42; con, control.

three miRNAs were predicted to bind with RNA transcripts of PPIAP43 and PPIAL4A (Table VI). Transcription changes of PPIAP43, PPIA and PPIAL4A following radiation are presented in Fig. 4. 
Table VII. Survival fractions of cell lines after 2 Gy radiation.

\begin{tabular}{lcccc}
\hline Cell line & $\begin{array}{c}\text { PPIAP43 } \\
\text { over-transcribed }\end{array}$ & Group & $\begin{array}{c}\text { Survival fraction after 2 Gy } \\
\gamma \text {-radiation (3) }\end{array}$ & $\begin{array}{c}\text { Survival fraction after 2 Gy } \\
\text { X-radiation (10) }\end{array}$ \\
\hline H69 & Yes & A & & 0.23 \\
H146 & Yes & A & 0.6 & 0.18 \\
H187 & Yes & A & & 0.37 \\
H209 & Yes & A & & 0.72 \\
H526 & No & B & 0.7 & \\
D153 & No & B & & \\
\hline
\end{tabular}

PPIAP43, peptidyl-prolyl cis-trans isomerase A pseudogene 43.

\section{Discussion}

Radiation therapy remains a major form of treating patients with SCLC. However, radio-sensitivity amongst different SCLC cell lines vary. Therefore, identifying potential biomarkers for predicting radio-sensitivity, may help predict a patient's response to this mode of treatment. The results of the present study identified a lncRNA transcribed from pseudogene PPIAP43, which was overexpressed in several SCLC cell types (group A) following 2 Gy gamma radiation by $\geq 2$-fold compared with the non-irradiated control group by bioinformatic processing of a GEO dataset. In addition, other SCLC cell lines (group B) exhibited no gene upregulation following radiation. Although the statuses of cytotoxicity column were 'YES' in groups A and B in the table of experiment descriptors displayed by the BRB ArrayTools, the original study using this GEO dataset demonstrated that the survival fraction of cell line H146 in group A and D153 in group B were 60 and 70\%, respectively (Table VII) (6). Another previous study revealed that the 2 Gy X-RAY survival fractions of H69, H187 and H209 were $0.23,0.18$ and 0.37 , respectively, compared with 0.72 in H526 cells (Table VII) (15). These two studies demonstrated that the survival fractions following $2 \mathrm{~Gy}$ ionized radiation in cell lines in group A were lower compared with those in group $\mathrm{B}$, although survival fraction values varied based on the irradiation type, cell type and other factors. These results suggest that the radiation sensitivity was different in the two groups. Therefore, the transcription change models of PPIAP43 before and after radiation may serve as a potential marker for classifying the two groups of SCLC cell lines into high and low sensitivity groups.

Further investigation revealed that pseudogene PPIAP43 was located on 11q22.1, and the only nearby protein-coding gene, which may be affected by transcription of PPIAP43, was ARHGAP42. Previous studies demonstrated that lncRNA may affect the transcription of adjacent genes by targeting activators and repressors of mRNA transcription $(13,14)$. According to these results, PPIAP43 may affect the transcription of its adjacent gene ARHGAP42 by binding with nucleotide-binding proteins. However, Pearson's correlation analysis of transcriptional changes between PPIAP43 and ARHGAP42 was -0.584 , with significance of 0.099 ; with former studies suggesting that the transcription of IncRNA is positively correlated with transcription of nearby protein-coding genes if there is an effect on adjacent protein-coding genes by lncRNA transcription $(13,14)$, which indicated that PPAP43 did not statistically affect ARHGAP42 on a transcriptional level.

Another functional role of PPIAP43 is competing endogenous RNA. In this model, the RNA transcript of a pseudogene may act as a decoy to target and capture miRNAs, which can bind with RNAs of the pseudogenes and their gene counterparts $(16,17)$. For example, in the case of the RNA of pseudogene phosphatase and tensin homolog pseudogene 1 (PTENP1), the expression level of the tumor suppressor gene PTEN is upregulated when the PTENP1 RNA is upregulated which results in decreased cancer cell proliferation; similarly, the expression level of the oncogene B-Raf proto-oncogene is upregulated when PTEN pseudogene 1 RNA is upregulated, which leads to increased proliferation of cancer cells $(13,14)$. In the present study, an aligned section on PPIA mRNA and RNA transcript of PPIAP43 to which miRNA could bind was identified. In addition, miRNA hsa-miR-876-3p was predicted by miRDB to be capable of binding with PPIA and PPIAP43 (18-26). The binding ability of this miRNA has been confirmed by 21 experiments (18-26).

In addition, increase of RNA transcript PPIAP43 lead to upregulation of RNA transcript of PPIA. The upregulated transcription of other PPIA pseudogenes in the studied cell lines also suggested that the cross-talk between PPIA RNA and its pseudogenes mediated by miRNAs may be the dominant function pattern of PPIAP43. This suggests that under radiation stress, radiation-sensitive cells may generate more free radicals including hydroxyl radicals (27-29) compared with insensitive cells, therefore upregulating expression of PPIA (30). With the decoy effect of upregulated RNAs of PPIA pseudogenes, the binding between miRNAs and the mRNA of PPIA is decreased, the survival of PPIA mRNA is prolonged, and therefore the expression of PPIA protein is increased (17). Cyclosporine can bind with PPIA (also termed Cyclophilin A, CyPA) and other cyclophilins to suppress organ rejection by coupling with cyclosporin (31). Overexpression of PPIA is associated with poor response to inflammatory disease, cancer metastasis progression and aging (32). In lung cancer, exogenous PPIA protein stimulates H446 cell growth, whereas PPIA knockdown may lead to slower growth, decreased proliferation and increased apoptosis in cell lines ADLC-5M2 and LC-103H $(25,26,33,34)$. Therefore, the overexpressed RNAs of PPIAP43 and other PPIA pseudogenes may serve as a remedy for reactive oxygen 
species (ROS) accumulation induced by ionizing radiation to rescue the sensitive cancer cells by the decoy effect on miRNAs. In addition, there may be other resistance mechanisms used by less radio-sensitive cell types in group B. Nevertheless, the upregulated transcription of PPIAP43 and the slightly downregulated PPIA transcription in $\mathrm{H} 526$ cells suggests that this cell type may be classified as high-sensitivity, although the upregulated transcriptional change of PPIAP43 in H526 was $<2$-fold following irradiation. This may have been due to the different conditions of gamma ray, from which transcription data was collected, and X-ray, from which the survival fraction data was collected, although there may be other influencing factors that still need to be identified.

There were certain limitations to the present in silico study. First, the transcription levels of PPIAP43 in the H526 cell line was not as distinct compared with those in the cell lines in group A as compared with the levels in the other cell lines in group B. Second, the survival fractions of the cell lines were obtained from different studies with incomplete information. Third, epigenetics may be also involved in the function of PPIAP43 (35), which was not considered in the present study.

A previous study demonstrated that an increased Ki-67 proliferation index may represent a predictive factor for increased tumor radio-sensitivity (36). The present study identified a potential radio-sensitivity indicator for SCLC cell lines following early radiation in vitro. The results of this study revealed that a $\geq 2$-fold transcriptional change of pseudogene PPIAP43 following irradiation with 2 Gy gamma radiation may represent a predictive factor for increased tumor radiosensitivity. To describe this association in detail, additional studies with more cell types and experimental methods are required. Further in vivo studies, particularly studies involving blood tests, may provide a basis to use the lncRNA identified in the present study to help early identification of less radiation-sensitive SCLC types and reduce the unnecessary radiation side effects in patients with SCLC.

\section{Acknowledgements}

Not applicable.

\section{Funding}

This study was supported by The National Key Research and Development Program of China (grant. no. 2018YFC1313200).

\section{Availability of data and materials}

The datasets used and/or analyzed during the present study are available from the corresponding author on reasonable request.

\section{Authors' contributions}

JY conceived and designed the study. SW conducted the experiment and analysis, and drafted the manuscript. JY and SW reviewed, edited and approved the manuscript.

\section{Ethics approval and consent to participate}

Not applicable.

\section{Patient consent for publication}

Not applicable.

\section{Competing interests}

The authors declare that they have no conflicts of interest.

\section{References}

1. Gazdar AF, Bunn PA and Minna JD: Small-cell lung cancer: What we know, what we need to know and the path forward. Nat Rev Cancer 17: 725-737, 2017.

2. Sabari JK, Lok BH, Laird JH, Poirier JT and Rudin CM: Unravelling the biology of SCLC: Implications for therapy. Nat Rev Clin Oncol 14: 549-561, 2017.

3. Hendricks MV, Sheils WC and Davis WB: Radiation-induced lung injury. Clin Pulm Med 6: 287-295, 1999.

4. Videtic GM, Stephans KL, Woody NM, Pennell NA, Shapiro M, Reddy CA and Djemil T: Stereotactic body radiation therapy-based treatment model for stage I medically inoperable small cell lung cancer. Pract Radiat Oncol 3: 301-306, 2013.

5. Jassem J: The rote of radiotherapy in lung cancer: Where is the evidence? Radiother Oncol 83: 203-213, 2007.

6. Owonikoko TK, Zhang G, Deng X, Rossi MR, Switchenko JM, Doho GH, Chen Z, Kim S, Strychor S, Christner SM, et al: Poly (ADP) ribose polymerase enzyme inhibitor, veliparib, potentiates chemotherapy and radiation in vitro and in vivo in small cell lung cancer. Cancer Med 3: 1579-1594, 2014.

7. Simon R, Lam A, Li MC, Ngan M, Menenzes S and Zhao Y: Analysis of gene expression data using BRB-ArrayTools. Cancer Inform 3: 11-17, 2007.

8. Huang da W, Sherman BT and Lempicki RA: Systematic and integrative analysis of large gene lists using DAVID bioinformatics resources. Nat Protoc 4: 44-57, 2009.

9. Huang da W, Sherman BT and Lempicki RA: Bioinformatics enrichment tools: Paths toward the comprehensive functional analysis of large gene lists. Nucleic Acids Res 37: 1-13, 2009.

10. Bellucci M, Agostini F, Masin M and Tartaglia GG: Predicting protein associations with long noncoding RNAs. Nat Methods 8: 444-445, 2011.

11. Wong $\mathrm{N}$ and Wang $\mathrm{X}$ : miRDB: An online resource for microRNA target prediction and functional annotations. Nucleic Acids Res 43: D146-D152, 2015.

12. Wang $X$ : Improving microRNA target prediction by modeling with unambiguously identified microRNA-target pairs from CLIP-ligation studies. Bioinformatics 32: 1316-1322, 2016.

13. Goodrich JA and Kugel JF: Non-coding-RNA regulators of RNA polymerase II transcription. Nat Rev Mol Cell Biol 7: 612-616, 2006.

14. Luo S, Lu Y, Liu L, Yin Y, Chen C, Han X, Wu B, Xu R, Liu W, Yan $\mathrm{P}$, et al: Divergent lncRNAs regulate gene expression and lineage differentiation in pluripotent cells. Cell Stem Cell 18: 637-652, 2016.

15. Carmichael J, Degraff WG, Gamson J, Russo D, Gazdar AF, Levitt ML, Minna JD and Mitchell JB: Radiation sensitivity of human-lung cancer cell-lines. Eur J Cancer Clin Oncol 25: 527-534, 1989.

16. Karreth FA, Reschke M, Ruocco A, Ng C, Chapuy B, Léopold V, Sjoberg M, Keane TM, Verma A, Ala U, et al: The BRAF pseudogene functions as a competitive endogenous RNA and induces lymphoma in vivo. Cell 161: 319-332, 2015.

17. Poliseno L, Salmena L, Zhang J, Carver B, Haveman WJ and Pandolfi PP: A coding-independent function of gene and pseudogene mRNAs regulates tumour biology. Nature 465: 1033-1038, 2010.

18. Griffiths-Jones S, Grocock RJ, van Dongen S, Bateman A and Enright AJ: miRBase: MicroRNA sequences, targets and gene nomenclature. Nucleic Acids Res 34: D140-D144, 2006.

19. Landgraf P, Rusu M, Sheridan R, Sewer A, Iovino N, Aravin A, Pfeffer S, Rice A, Kamphorst AO, Landthaler M, et al: A mammalian microRNA expression atlas based on small RNA library sequencing. Cell 129: 1401-1414, 2007.

20. Lam LT, Lu X, Zhang H, Lesniewski R, Rosenberg S and Semizarov D: A MicroRNA screen to identify modulators of sensitivity to BCL2 inhibitor ABT-263 (Navitoclax). Mol Cancer Ther 9: 2943-2950, 2010. 
21. Wang RYL, Weng KF, Huang YC and Chen CJ: Elevated expression of circulating miR876-5p is a specific response to severe EV71 infections. Sci Rep 6: 24149, 2016.

22. Bao L, Lv L, Feng J, Chen Y, Wang X, Han S and Zhao H: MiR-876-5p suppresses epithelial-mesenchymal transition of lung cancer by directly down-regulating bone morphogenetic protein 4. J Biosci 42: 671-681, 2017.

23. Ayub Khan SM, Few LL and See Too WC: Downregulation of human choline kinase $\alpha$ gene expression by miR-876-5p. Mol Med Rep 17: 7442-7450, 2018.

24. Kozomara A and Griffiths-Jones S: miRBase: Integrating microRNA annotation and deep-sequencing data. Nucleic Acids Res 39: D152-D157, 2011.

25. Xu Q, Zhu Q, Zhou Z, Wang Y, Liu X, Yin G, Tong X and Tu K: MicroRNA-876-5p inhibits epithelial-mesenchymal transition and metastasis of hepatocellular carcinoma by targeting BCL6 corepressor like 1. Biomed Pharmacother 103: 645-652, 2018.

26. Wang Y, Xie Y, Li X, Lin J, Zhang S, Li Z, Huo L and Gong R: MiR-876-5p acts as an inhibitor in hepatocellular carcinoma progression by targeting DNMT3A. Pathol Res Pract 214: 1024-1030, 2018.

27. Joiner MC and van der Kogel A (eds): Basic Clinical Radiobiology 5th Edition. CRC Press/Taylor \& Francis Group (Boca Raton, FL, USA), pp 188-205, 2019.

28. Wallace SS: Enzymatic processing of radiation-induced free radical damage in DNA. Radiat Res 150 (5 Suppl): S60-S79, 1998.

29. Riley PA: Free radicals in biology: Oxidative stress and the effects of ionizing radiation. Int J Radiat Biol 65: 27-33, 1994.
30. Suzuki J, Jin ZG, Meoli DF, Matoba T and Berk BC: Cyclophilin A is secreted by a vesicular pathway in vascular smooth muscle cells. Circ Res 98: 811-817, 2006.

31. Matsuda S and Koyasu S: Mechanisms of action of cyclosporine. Immunopharmacology 47: 119-125, 2000.

32. Nigro P, Pompilio G and Capogrossi MC: Cyclophilin A: A key player for human disease. Cell Death Dis 4: e888, 2013.

33. Yang H, Chen J, Yang J, Qiao S, Zhao S and Yu L: Cyclophilin A is upregulated in small cell lung cancer and activates ERK1/2 signal. Biochem Biophys Res Commun 361: 763-767, 2007.

34. Howard BA, Furumai R, Campa MJ, Rabbani ZN, Vujaskovic Z, Wang XF and Patz EF Jr: Stable RNA interference-mediated suppression of Cyclophilin A diminishes non-small-cell lung tumor growth in vivo. Cancer Res 65: 8853-8860, 2005.

35. Sanchez-Elsner T, Gou D, Kremmer E and Sauer F: Noncoding RNAs of trithorax response elements recruit Drosophila Ash1 to ultrabithorax. Science 311: 1118-1123, 2006.

36. Ishibashi N, Maebayashi T, Aizawa T, Sakaguchi M, Nishimaki H and Masuda S: Correlation between the Ki-67 proliferation index and response to radiation therapy in small cell lung cancer. Radiat Oncol 12: 16, 2017.

This work is licensed under a Creative Commons Attribution-NonCommercial-NoDerivatives 4.0 International (CC BY-NC-ND 4.0) License. 